\title{
MOTIVATION AND EMPOWERMENT OF EMPLOYEES AS IMPORTANT FACTORS FOR THE SUCCESS OF THE ENTERPRISE
}

\author{
Labeat Mustafa ${ }^{1}$
}

\begin{abstract}
Motivation of the employee is seen as important factor that impacts on growth of enterprise success. Link between employee motivation as well as performance seems to be very clear, thus relation between them in fact is very complex.

To motivate employees' managers should find creative ways as much as possible.

Good relations among working staff impacts in growth of motivation which makes them active, giving the maximum of themselves to perform at work and resulting success of the enterprise. A favorable climate and environment at the ambience where work is being done is very important for success of enterprise.

Employee's empowerment is considered a new style of managing which could affect the increase efficiency and effectiveness at the enterprise.

Empowerment creates for employees feeling of autonomy which increases their satisfaction at work, makes them feel more comfortable and feel good at work because it will develop feeling of trust and value.
\end{abstract}

Key words: Motivation, empowerment, working staff, success, enterprise.

Jell Codes: M12 - Personnel Management, Executives, Executive Compensation; M11 - Production Management; M59 - other; 01 - Economic Development

\section{Introduction}

In terms of contemporary economics, most enterprises are making efforts to survive due to changing environment and fierce market.

Employee motivation is an important factor for increasing employee performance and enterprise success. Many researchers point out that there is a positive relationship between employee motivation and success of the enterprise.

A company can achieve its full potential only by making use of all the financial, physical and human resources available. This is achieved through employee motivation to fulfil their duties. In this way enterprise begins to reflect positively, because everyone is doing their best to fulfil their duties.

The concept of employee empowerment has been given greater attention since the 1980s, due to its high impact on organizational effectiveness and innovation. (Spreitzer, G. M., 1995)

Empowering employees can be a powerful tool for organizations. This new management style can increase efficiency and effectiveness within the organization and employee productivity.

Goal of this study is to show importance of motivation and employees' empowerment as independent variables for achieving success (as dependent variable) at the enterprises in Republic of Kosovo.

\section{Literature Review}

\footnotetext{
${ }^{1}$ Dr.Sc. Labeat Mustafa, professor assistant at University for Business and Technology - UBT, Prishtina, Kosovo,email: labeat.mustafa@ubt-uni.net
} 
ISSN 2661-2666 (Online) International Scientific Journal Monte (ISJM) DOI: 10.33807/monte.20211897 Volume 4, (No).2 (2021): April

\section{Employee motivation and enterprise success}

Aim of all enterprises is to be successful in current highly competitive environment, under these circumstances' enterprises strive to receive and retain best employees, given their importance to effectiveness and success of the enterprise. Enterprises should establish strong and positive relationships with employees in achieving successfully their goals.

Because all individuals are not the same, managers need to implement different strategies to motivate them. For example, some employees may be motivated by financial incentives, while others may be motivated by job satisfaction or a better working environment. Knowing that people have different needs, some are driven by achievements, others focus on security so if managers are able to understand, feel, anticipate and control needs and behaviors of employees, they should also know what do employees want from their jobs. So, for a manager it is essential to understand what really motivates employees without merely making assumptions. (Good, I., O., 2013).

At first link between employee motivation and performance seems to be quite clear. The relationship between these two things is actually much more complex. Realistically duties of employees in most of the time can be tedious, repetitive and quite boring. (Silberman, J., 2013). For this reason, managers need to find creative ways to keep their employees motivated as much as possible.

Motivation facilitates employees to achieve goals for their own development. Since employee meets some initial goals, he understands clear link between efforts and results, which will further motivate him to continue at a higher level.

Employee satisfaction is important to any enterprise and therefore is factor that leads to progress or regression. In absence of a stimulus plan, employees will not be willing to meet their objectives, so managers should look at how to encourage them through promotion opportunities, monetary and nonmonetary bonuses, etc. (Silberman, J., 2013)

In order to achieve best results, employees must have a perfect balance between ability and readiness to work. Such equilibrium can lead to increased productivity, lower costs and overall efficiency improvement so all of this can be achieved through motivation.

\section{Some ways to motivate employee staff}

According to Charles P. Garcia (2009) strong leader is the one who gives the maximum of himself and encourages employees to do their best, more than when they are rewarded with money. Some of the ways of motivating employees in the enterprise according to him are:

- Giving energy to the employee team. Rather than manager taking energy from others, he should make effort every day to deliver positive energy and encourage passion of employees in the workplace.

- People are in the first place. No organization is more important than people working on it.

- Acting with integrity. It is very important that when talking about the organization, employees or managers feel proud of their organization.

- To be excellent in communication. Leaders have influence to impact others and this cannot be achieved without effective communication.

- To be a careful listener. It is very important to have patience to listen carefully and still make decision that you think is best by convincing others that you are ok.

- Solve problems. At the door of the leader should be hanged an inscription "Do not bring me problems but bring their solutions".

- Guide by experience and competence and not by the title or position you have in the enterprise. Guide your employees, encourage them and become a partner with them, enterprise will be secured in achieving success. If you want your enterprise to survive in the tough economy, this is exactly the kind of leadership that motivates employees and is needed to your organization. (Charles P. Garcia, 2009 cited according to Zwilling M., 2012) 
ISSN 2661-2666 (Online) International Scientific Journal Monte (ISJM) DOI: 10.33807/monte.20211897 Volume 4, (No).2 (2021): April

\section{Empowering employees and enterprise success}

Empowering employees is giving a certain degree of autonomy and responsibility to employees to make decisions about their specific organizational tasks. Empowerment enables decisions to be taken from low levels of an organization in which employees have a specific view of issues and problems organization faces at a certain level. (Grimsley, Sh., 2016) Some empowering researchers have identified it as a form of decentralization involving transfer of important decisions to subordinates (Corsun \& Enz, 1999) and implies fall of traditional hierarchical structure. (Javanmard, H., \& Havasi, S., 2013).

Challenges, such as changing environment, sophisticated technology, need for rapid decision-making and frequent changes and have created the need among organizations to change their traditional management practices (leadership and control) into democratic structures that employees get greater autonomy, trust and freedom to make decisions. Such democratic structures will not be effective if employees do not have a feeling of empowerment.

By empowering employees, leaders and managers have the freedom to dedicate their time to more important things. (Spreitzer, G., M., 1995)

Empowering brings many benefits to employees as well as to organization. This makes them feel better about their contribution to the organization, it encourages employees to think of finding better ways to carry out their jobs and this gives employees a sense of trust in themselves and their enterprise (organization). (Bourke, 1998)

According to Altizer (1993) some of empowerment benefits are: Rapid response to environmental change; Improving productivity and quality at work; Creating and strengthening a positive working culture; Encouraging employees to use talent to be more creative; The fastest solution to problems; Maintaining pride and morale of employees; It makes Employees more responsible; It creates flexibility and innovation; Facilitating knowledge exchange and Increasing job satisfaction. (Altizer, C., 1993).

Employee empowerment begins with the strategic concept between people, tasks, technology, information processes, bonuses and organizational structure for which all must be coordinated in one line so that organization can be successful.

Empowering employees leads to increased competitiveness, increased accountability, risk taking, increased innovation, reduced losses and encourages the desire to improve overall performance. Employees with strong organizational engagement are emotionally tied to the organization and have a great desire to contribute significantly to its success.

Empowerment increases individual engagement and dedication to working in groups or teams, contributes to improving group performance, affects interpersonal interaction, enhances performance and degree of individual satisfaction. Employee empowerment therefore inspires change and increases level of employee's engagement in workplace, thus influencing achievement of enterprise's success. (Sahoo, K., Ch., \& Das, S. 2011)

Empowered employees have responsibilities, they create feelings of ownership in their behaviour (Miles et al, 1987), see themselves as active persons who are able to undertake creative actions, independently decide and promote new ideas (Roberts, 1992). Employee empowerment factors are divided into two categories: factors that increase motivation and improve employee skills and factors that offer ease to improve quality of customer services (Shafi, 2006).

Empowering employees encourages and motivates employees to perform at an optimum level. If organization seeks ways to speed up processes and produce quality products or quality services, it should focus on empowering employees. When leader shows confidence in his employees, gives them timely information and gives them authority to find solutions, employees will be able to solve problems faster than employees without empowerment. (Anaejionu, R., 2015)

When an employee has a sense of achievement and feels appreciated, he is more likely to engage in critical and creative thinking. He will feel more capable and inspired to set in unconventional situations in a creative way, which leads to success of the enterprise. When an employee is empowered to think for 
ISSN 2661-2666 (Online) International Scientific Journal Monte (ISJM) DOI: $10.33807 /$ monte.20211897 Volume 4, (No).2 (2021): April

himself and to take initiatives, he can find creative and unique ways for quality services, to make processes or policies effective by influencing success of the enterprise market.

Empowerment creates employees a sense of autonomy, which increases their satisfaction at work. They will be more comfortable and feel better at work, because they feel sense of trust and value. A happy employee provides better customer service and gives a better impression to organization with anyone who communicates. This turns into personal or career growth for employees of organization and achievement of the enterprise's success. (NOA Human Resources, 2008²)

In a world where technology changes every day and consumers can find information, products and services in ever-changing ways, employees need to make quick decisions that are in the best interests of organization. If management has spent time and effort by providing trainings in decision-making, employees are more likely to respond to changes quickly and find new ways to meet customer requirements.

Employees show loyalty if they are well-trained, supported, respected, heard and evaluated within an organization. They are more likely to work hard and promote company when given the opportunity. They are also less likely to leave the company and are more likely to recommend other qualified individuals if they have new jobs. (Anaejionu, R., 2015)

\section{Methodology}

For the realization of this paper was used empirical method, based on the experiences of managers and operational employees of various businesses in the Republic of Kosovo.

Was used quantitative method and were presented the results from the analyzes made in commercial and manufacturing enterprises. Data collection was done through a questionnaire.

The sources of secondary data are various international articles and journals, which represent valuable studies of authors who have dealt with these topics. Theoretical books were also used which were important for the realization of this work.

The literature review is divided into two parts which explain motivation and empowerment as important factors in achieving success in the enterprise.

\section{Results}

In order to assess the role and importance for motivation and empowerment in success of the enterprise, 220 questionnaires were provided to managers and entrepreneurs (in August - December 2020) in 110 small and medium-sized commercial and manufacturing enterprises in the seven main cities Kosovo: Prishtina, Peja, Gjakova, Prizren, Mitrovica, Gjilan, and Ferizaj.

From the survey results comes out that $73 \%$ of managers agree that motivation affects positively growth of employees performance and enterprise success. $20 \%$ of managers disagree that motivation positively affects the company's success, while 7\% of managers are neutral in their responses (either yes or no).

\section{Graphics 1. Motivation as an important factor of success}

\footnotetext{
${ }^{2}$ www.wfm.noaa.gov/pdfs/Model_Guide_Generalist.pdf
} 


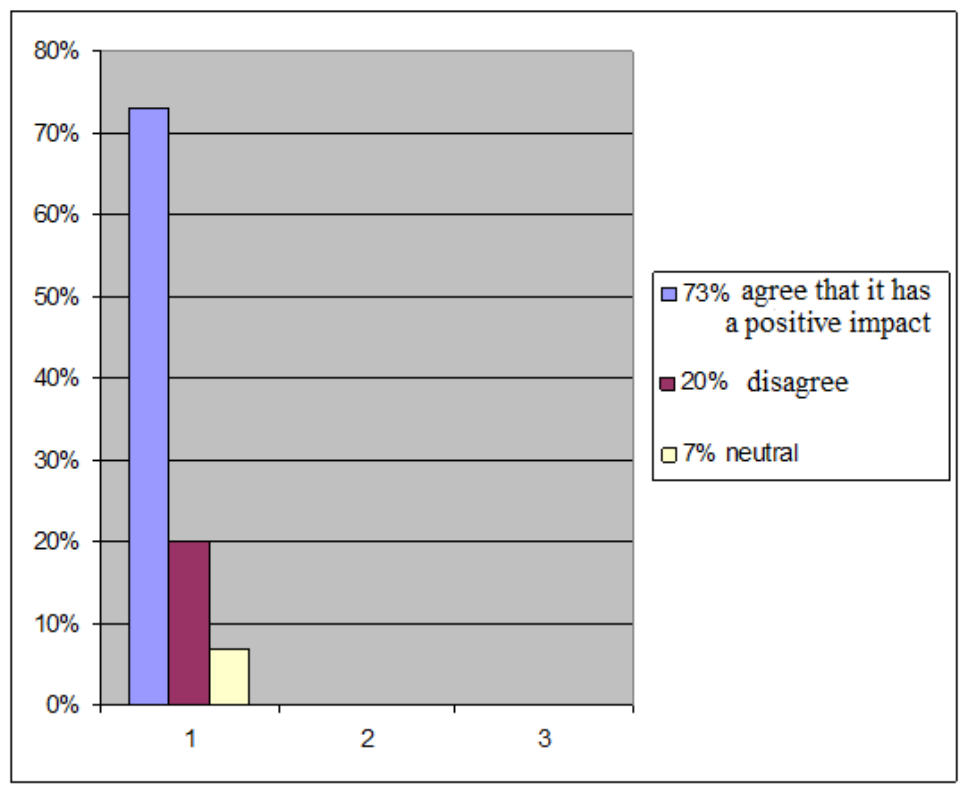

Source: Mustafa, L., 2020

Managers over the last two years have applied different ways of motivation that have brought increase to the enterprise's success.

Out of $73 \%$ of managers who responded that motivation positively affects the company's success, $38 \%$ of them did not consider financial means as main factor for motivation but applied other methods that have positively impacted increase in efficiency of employee's performance. It is worth mentioning that salaries or financial rewards have been applied under previous agreements and contracts. Some of the applied methods for employee motivation were based on: creating positive energy in working environment, evaluating creative ideas of employees, selecting best employee, adjusting working hours to suit needs of employees and giving freedom to act in certain situations.

Were applied combined ways on $46 \%$ from them:

- Additional payments(team and individual) in case of higher achievement than planned,

- possibility of free expression of opinions, proposals,

- $\quad$ their participation in dividing duties and

- granting freedom to act in certain situations.

$16 \%$ of managers (in case enterprise has achieved positive results at certain times); to motivate employees have organized lunches or dinners, one-day walks during weekends in attractive touristic places.

\section{Graphics no.2 Applied motivation forms}




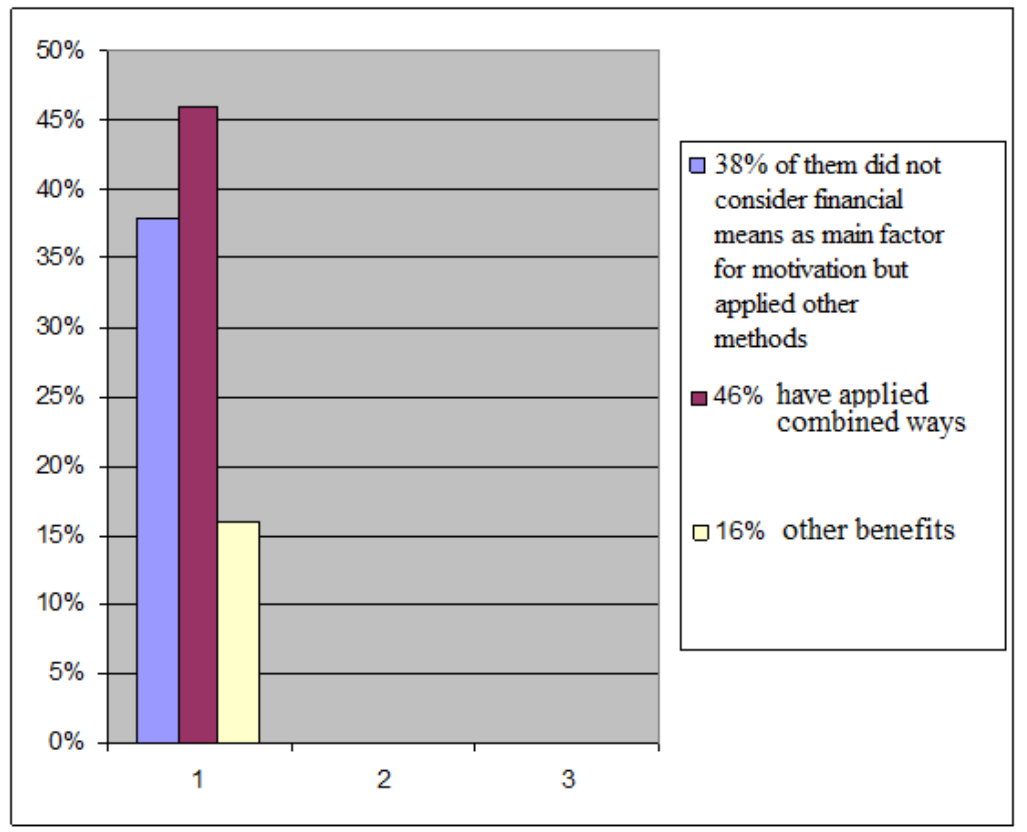

Source: Mustafa, L., 2020

Out of the results of 220 questionnaires distributed in 105 commercial and manufacturing enterprises for implementation of this study, 56\% of managers interviewed agree that empowerment of employees positively influences achievement of enterprise success, $29 \%$ do not agree that empowerment positively affects, while $15 \%$ managers were neutral on this question. (Mustafa, L. 2020)

\section{Graphics no.3: Empowerment, influencing factor for enterprise success}

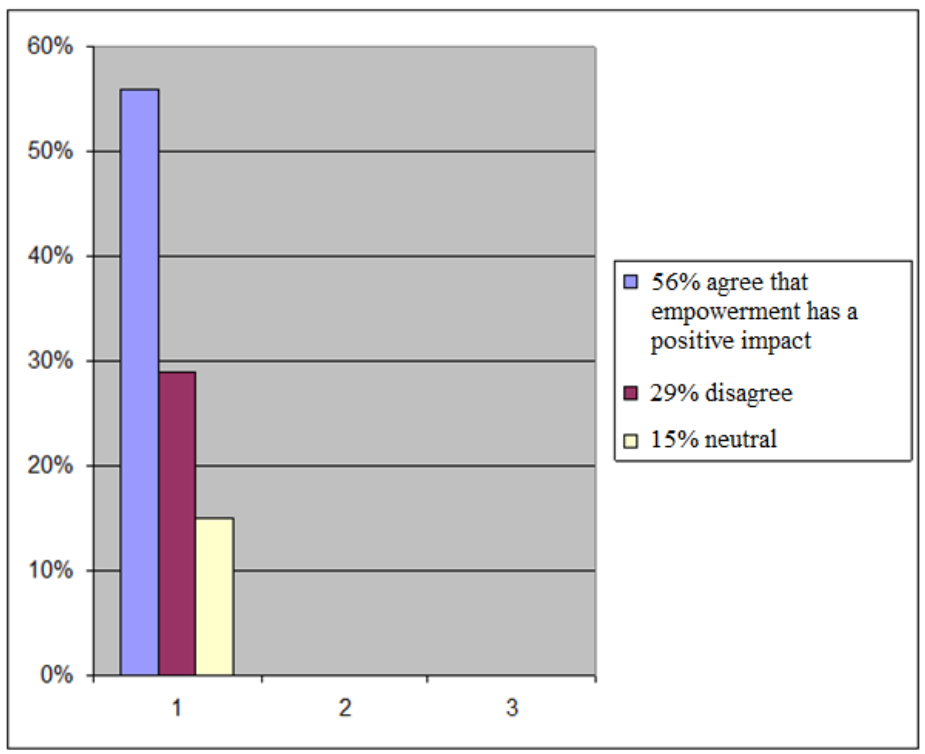

Source: Mustafa, L., 2020

Out of the $56 \%$ of managers who answered that motivation positively affects enterprise success, $66 \%$ of them have applied employee empowerment over past two years, which has positively resulted in achieving 
ISSN 2661-2666 (Online) International Scientific Journal Monte (ISJM) DOI: 10.33807/monte.20211897 Volume 4, (No).2 (2021): April

success. 34\% did not apply employee empowerment, but agreed that it positively contributes to the success growth. (Mustafa, L. 2020)

Graphics no.4: Managers who applied empowerment and those who did not apply but responded positively

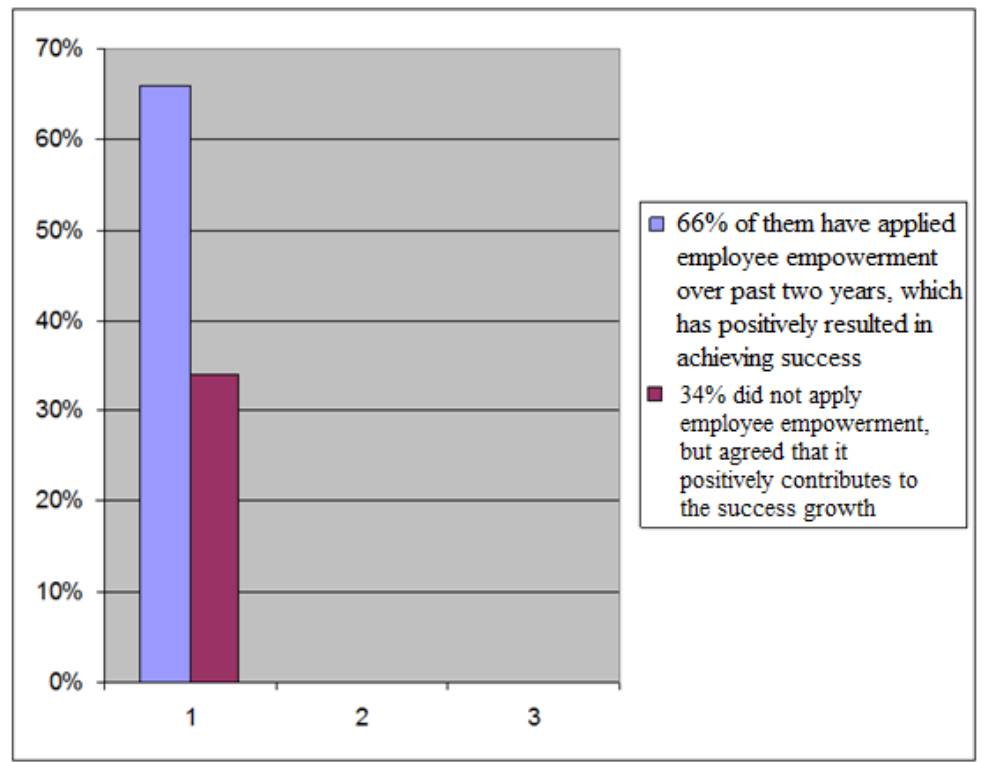

Source: Mustafa, L., 2020

From $29 \%$ of managers who disagreed that empowerment positively contributes to achieving enterprise success, $78 \%$ of them had applied employee empowerment and according to them, did not result either positively or negatively in achieving enterprise success. $22 \%$ of them did not apply employee empowerment, but were of the opinion that employee empowerment did not positively affect success of the enterprise. (Mustafa, L. 2020)

Graphics no. 5: Managers who applied empowerment and those who did not apply but responded negatively

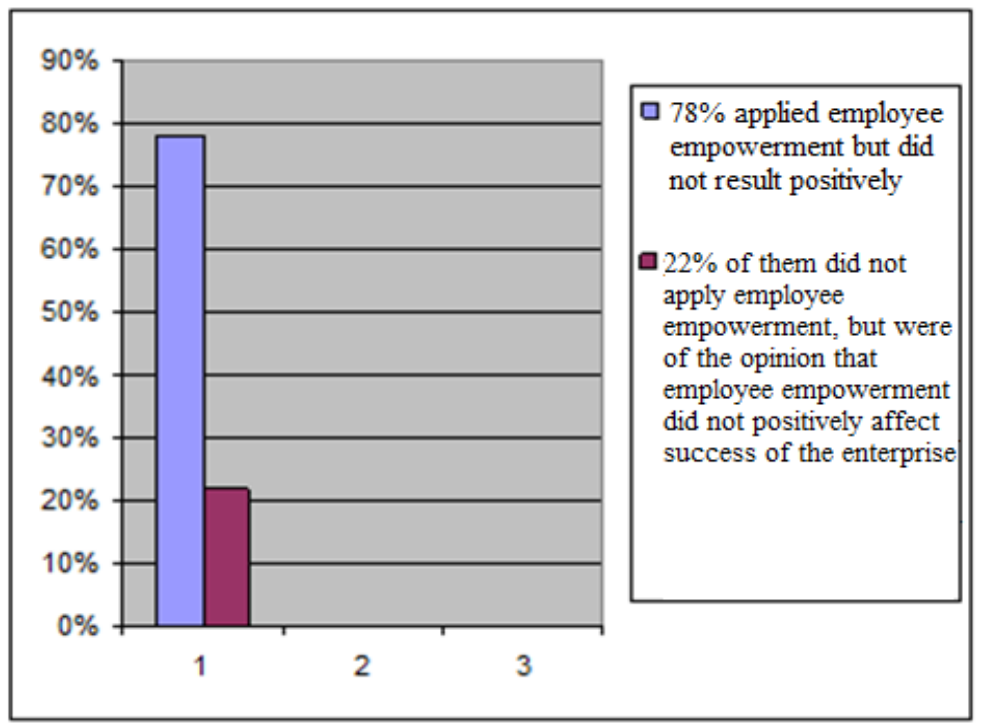

Source: Mustafa, L., 2020 
ISSN 2661-2666 (Online) International Scientific Journal Monte (ISJM) DOI: 10.33807/monte.20211897 Volume 4, (No).2 (2021): April

\section{Conclusions and recommendations}

- Employee motivation is seen as an important factor influencing enterprise success.

- Non-existence of sound relationships between staff impacts the lack of motivation and makes employees more passive, more reluctant to avoid giving maximum of themselves to perform at work and resulting in company's failure to succeed.

- For enterprise success must be created an appropriate ambience and climate in working environment.

- Appropriate climate and good inter-human employee relations reports affect employee engagement, respectively motivation which will result in maximum engagement of employee in performing tasks.

- Managing staff should be creative, apply more contemporary management methods that will bring positive results to the enterprise.

- Empowering employees leads to increased competitiveness, increased accountability, risk taking, increased innovation, reduced losses and encourages desire to improve overall performance.

- Empowering of working staff has a positive impact on achieving results and success of enterprise because it helps working staff make more flexible decisions, not wasting time in decision making at certain times.

- Empowerment creates employees a sense of autonomy, which increases their satisfaction at work. They will be more comfortable and feel better at work, because they feel the sense of trust and value. A happy employee provides better customer service and gives a better impression to the organization with anyone who communicates.

- Empowering employees inspires change and increases the level of employee engagement at work by influencing achievement of enterprise success. 
ISSN 2661-2666 (Online) International Scientific Journal Monte (ISJM) DOI: 10.33807/monte.20211897

Volume 4, (No).2 (2021): April

\section{References}

- Bourke, J.F., (1998) “Employee Empowerment,” Dallas Business Journal, v.21, no.46.

- Dobre, Ovidiu-Iliuta, 2013, "Employee motivation and organizational performance", Review of Applied Socio - Economic Research, (Volume 5, Issue 1/ 2013 ), pg. 53

- Mustafa L., Management of enterprises in the conditions of contemporary economy (with special regard to small and medium enterprises of the Republic of Kosovo) - Doctoral Thesis, UET, Tirana, 2017

- Roberts, S.M. (1992). Human skills-keys to effectiveness. Cost Engineering (Morgantown, West Virginia), 34(11), 17-19.

- Sahoo, K., Ch. \& Das, S., (2011) "Employee Empowerment: A Strategy towards Workplace

Commitment", European Journal of Business and Management, pg. 46

- Shafi, A. (2006). The study of the relation between employee empowerment and organizational learning in the petroleum company, Dissertation of management. University of Teheran.

- Spreitzer, G.M., "Psychological Empowerment in the Workplace: Dimensions, Measurement, and Validation," Academy of Management Journal, v.21, no.46

- www.wfm.noaa.gov/pdfs/Model_Guide_Generalist.pdf

- http://smallbusiness.chron.com/empowerment-employees-becoming-important-organizations-11542.html 